\title{
Effects of a high-intensity intermittent training program on aerobic capacity and lipid profile in trained subjects
}

This article was published in the following Dove Press journal:

Open Access Journal of Sports Medicine

17 October 2014

Number of times this article has been viewed

\author{
Nejmeddine Ouerghi' ${ }^{1,2}$ \\ Marwa Khammassi' \\ Sami Boukorraa' \\ Moncef Feki² \\ Naziha Kaabachi ${ }^{2}$ \\ Anissa Bouassida ${ }^{1,3}$ \\ 'Research Unit, Sportive Performance \\ and Physical Rehabilitation, High \\ Institute of Sports and Physical \\ Education of Kef, University of \\ Jendouba, Kef, Tunisia, ${ }^{2}$ Laboratory \\ of Biochemistry, Rabta Hospital, \\ Faculty of Medicine of Tunis, El \\ Manar University, Tunis, ${ }^{3}$ Physiology \\ Laboratory, Faculty of Medicine Ibn el \\ Jazzar, Sousse, Tunisia
}

Correspondence: Nejmeddine Ouerghi Research Unit, Sportive Performance and Physical Rehabilitation, High Institute of Sports and Physical Education of Kef, University of Jendouba, Kef, Tunisia

Tel +21625300232

Email najm_ouerghi@hotmail.com
Background: Data regarding the effect of training on plasma lipids are controversial. Most studies have addressed continuous or long intermittent training programs. The present study evaluated the effect of short-short high-intensity intermittent training (HIIT) on aerobic capacity and plasma lipids in soccer players.

Methods: The study included 24 male subjects aged 21-26 years, divided into three groups: experimental group 1 (EG1, $\mathrm{n}=8$ ) comprising soccer players who exercised in addition to regular short-short HIIT twice a week for 12 weeks; experimental group 2 (EG2, n=8) comprising soccer players who exercised in a regular football training program; and a control group (CG, n=8) comprising untrained subjects who did not practice regular physical activity. Maximal aerobic velocity and maximal oxygen uptake along with plasma lipids were measured before and after 6 weeks and 12 weeks of the respective training program.

Results: Compared with basal values, maximal oxygen uptake had significantly increased in EG1 (from $53.3 \pm 4.0 \mathrm{~mL} / \mathrm{min} / \mathrm{kg}$ to $54.8 \pm 3.0 \mathrm{~mL} / \mathrm{min} / \mathrm{kg}$ at 6 weeks $[P<0.05]$ and to $57.0 \pm 3.2 \mathrm{~mL} / \mathrm{min} / \mathrm{kg}$ at 12 weeks $[P<0.001])$. Maximal oxygen uptake was increased only after 12 weeks in EG2 (from $52.8 \pm 2.7 \mathrm{~mL} / \mathrm{min} / \mathrm{kg}$ to $54.2 \pm 2.6 \mathrm{~mL} / \mathrm{min} / \mathrm{kg},[P<0.05]$ ), but remain unchanged in CG. After 12 weeks of training, maximal oxygen uptake was significantly higher in EG1 than in EG2 $(P<0.05)$. During training, no significant changes in plasma lipids occurred. However, after 12 weeks, total and low-density lipoprotein cholesterol levels had decreased (by about 2\%) in EG1 but increased in CG. High-density lipoprotein cholesterol levels increased in EG1 and EG2, but decreased in CG. Plasma triglycerides decreased by $8 \%$ in EG1 and increased by about 4\% in CG.

Conclusion: Twelve weeks of short-short HIIT improves aerobic capacity. Although changes in the lipid profile were not significant after this training program, they may have a beneficial impact on health.

Keywords: aerobic capacity, cholesterol, intermittent training, trained subjects, triglycerides

\section{Introduction}

The risk of cardiovascular diseases is clearly increasing worldwide. Taking the example of the USA from 2003 to 2006, The National Health and Nutrition Examination Survey estimated that $34 \%$ of adults (over the age of 20 years) met the criteria for metabolic syndrome. ${ }^{1}$

Practicing sport, especially aerobic training, has been proposed to be an effective mechanism for cardiovascular protection, but its effectiveness depends on many factors, including age, sex, body composition, and nutrition, as well as training duration and intensity. According to the literature, aerobic training improves plasma lipids, particularly in obese and overweight subjects. ${ }^{2-5}$ Data regarding the effects of aerobic 
training on the lipid profile in adults (trained and untrained) are controversial. Some studies have demonstrated the efficiency of aerobic training on aerobic capacity and the lipid profile, ${ }^{6-11}$ whereas other studies only showed an improvement in aerobic capacity after continued and intermittent aerobic training without any obvious modification of the lipid profile. ${ }^{12-18}$ The majority of previous studies testing the effects of aerobic training have focused on untrained subjects using a continuous or long-long intermittent training method. ${ }^{4,5,9,17,18}$ In particular, no study has considered plasma lipids in athletes using a short-short [15 second of work - 15 second of passive recovery (15-15)] intermittent training method. This study investigated the effects of a shortshort high-intensity intermittent training (HIIT) program on aerobic capacity and lipid profile in soccer players compared with untrained subjects.

\section{Materials and methods Subjects}

The study included 24 male subjects of mean age $22.9 \pm 1.73$ (range 21-26) years, divided into three groups: experimental group 1 (EG1), comprising eight trained subjects who followed a regular football training program with an additional intermittent (15-15) training program for 3 months; experimental group 2 (EG2), comprising eight trained subjects who followed a regular football training program without undergoing an additional intermittent training; and a control group (CG), comprising eight untrained subjects who did not practice regular physical activity.

The trained subjects were amateur soccer players belonging to the third division of the Tunisian championships competing at the regional level during the 2012-2013 season. All athletes trained for about 11 hours a week, and had been playing football for 8-12 years. They were randomly allocated to the experimental groups after stratification according to maximal aerobic velocity (MAV). All participants showed no physical anomaly during medical exam and gave their informed consent to participate in the study. The protocol was approved by the ethics committee at Rabta Hospital in Tunis.

\section{Study protocol}

The study was conducted during the competitive season from September to December 2012. The temperature varied between $10^{\circ} \mathrm{C}$ and $20^{\circ} \mathrm{C}$ and the humidity ranged from $40 \%$ to $70 \%$. Anthropometric measurements, training, and performance tests were undertaken on the football pitch and blood was drawn in the laboratory.

\section{Anthropometric measurements}

Weight $(\mathrm{kg})$ was measured by an electronic balance (Pharo 200) and height (m) was measured with a stadiometer. Body mass index (BMI) was calculated as follows:

$$
\text { BMI }\left(\mathrm{kg} / \mathrm{m}^{2}\right)=\text { weight } / \text { height }^{2} \text {. }
$$

\section{Estimation of $\mathrm{VO}_{2 \max }$ and MAV}

Maximal oxygen uptake $\left(\mathrm{VO}_{2 \max }\right)$ and MAV were measured using the Yo-Yo intermittent recovery test (level 1). This test was performed three times, ie, before, during, and after 3 months of the training program for the three groups. The Yo-Yo intermittent recovery test devised by Bangsbo ${ }^{19}$ and described by Krustrup et al, ${ }^{20}$ consists of repeated $2 \times 20$ meter runs back and forth between the starting, turning, and finishing line at a progressively increased speed controlled by audio bleeps from a computer. Between each bout of running, the subjects had a 10 -second active rest period, consisting of $2 \times 5 \mathrm{~m}$ of jogging. The test ended when the subjects twice failed to reach the finishing line on time. ${ }^{21}$

\section{Training program}

Intermittent training

The EG1 players participated in a short duration 15-15 HIIT program twice a week over 3 months, ie, Tuesday and Thursday each week during the competitive phase as an addition to usual training. From the MAV obtained by the Yo-Yo test, we established four working groups, and the players in each group ran for specific distances starting at a $105 \%$ MAV intensity for the first 3 weeks, with addition of 5\% intensity of MAV every 3 weeks (Table 1). During training, the Yo-Yo test was used to control and adjust the charges of work. The players alternated between 15 seconds of work and 15 seconds of passive recovery (15-15). Two 10-minute sets were held each session, ie, 20 work repetitions and 19

Table I Maximal aerobic velocity groups and run distances (in meters) according to the percentage of maximal aerobic velocity in experimental group

\begin{tabular}{|c|c|c|c|c|c|}
\hline & \multicolumn{5}{|c|}{ Distance covered in 15 seconds } \\
\hline & $100 \%$ & $105 \%$ & $110 \%$ & $115 \%$ & $120 \%$ \\
\hline & MAV & MAV & MAV & MAV & MAV \\
\hline \multicolumn{6}{|c|}{ MAV group, n (km/hour) } \\
\hline Group I, n=I (I3.I) & 54.6 & 57.3 & 60.1 & 62.8 & 65.5 \\
\hline Group 2, n=2 (15.6) & 64.8 & 68.0 & 71.3 & 74.5 & 77.8 \\
\hline Group 3, n=3 (16.2) & 67.7 & 71.0 & 74.4 & 77.8 & 81.2 \\
\hline Group 4, n=2 (17.6) & 73.2 & 76.9 & 80.6 & 84.2 & 87.8 \\
\hline
\end{tabular}

Abbreviation: MAV, maximal aerobic velocity. 
bouts of recovery for each set, and the inter-set recovery time was 3 minutes..$^{22,23}$

\section{Weekly training}

The two experimental groups (EG1 and EG2) trained together in a five-session per week program. A slagging session on Mondays consisted of 20 minutes of jogging at 50\% MAV and coordination work. On Tuesdays, the two groups performed technical-tactical exercises and coordination work. On Wednesdays, they participated in a muscle strengthening session and practice game to develop offensive and defensive skills. On Thursdays, they participated in tactical practice games. On Fridays, tactical sessions were held with exercises for agility and speed. In addition to this program, EG1 had intermittent run work (15-15) on Tuesdays and Thursdays. No training sessions were held on a Saturday, and Sundays are match days.

\section{Blood sampling and analysis}

Venous blood was drawn by venipuncture into heparinized tubes from fasting subjects at baseline and after 6 and 12 weeks. Blood samples were centrifuged at 2,000× $g$ for 20 minutes and plasma was kept frozen at $-20^{\circ} \mathrm{C}$ until analysis (within 6 months). Total cholesterol and high-density lipoprotein (HDL) cholesterol and triglycerides were assessed by the enzymatic colorimetric method on an Architect C8000 system (Abbott Laboratories, Abbott Park, IL, USA) using the respective reagent kits. Low-density lipoprotein (LDL) cholesterol was calculated using the Friedewald formula. ${ }^{24}$

\section{Statistical analysis}

The statistical analysis was performed using Statistical Package for the Social Sciences version 16.0 software (SPSS Inc., Chicago, IL, USA). Values for continuous variables are expressed as the mean \pm standard deviation (SD). The Kolmogorov-Smirnov test was applied to confirm normality. Continuous variables were compared using the paired-samples $t$-test in each group (EG1, EG2, or CG) and the independent-samples $t$-test between the groups.
$P<0.05$ based on two-sided calculation was considered to be statistically significant.

\section{Results}

\section{Anthropometric characteristics}

Twelve weeks of additional intermittent training (15-15) and regular football training (EG2) did not induce a significant variation in height. Weight and BMI decreased significantly in both experimental groups, but did not change significantly in the control group (Table 2).

\section{MAV and $\mathrm{VO}_{2 \max }$}

Basal MAV and $\mathrm{VO}_{2 \max }$ were significantly higher $(P<0.001)$ in football players than in untrained subjects. Compared with basal values (before training), the additional intermittent 15-15 training induced a significant improvement in MAV and $\mathrm{VO}_{2 \max }$ after 6 weeks and further improvement after 12 weeks. For EG2, the improvement was only detected after 12 weeks of regular training. MAV and $\mathrm{VO}_{2 \max }$ remained unchanged after both 6 and 12 weeks in the control group (Figure 1).

\section{Lipid profile}

Basal plasma lipid concentrations did not differ significantly between the three groups. The lipid profile showed nonsignificant changes after 6 and 12 weeks of the training program in all groups. After 12 weeks, plasma total cholesterol and LDL cholesterol levels decreased by about $2 \%$ in EG1, remained stable in EG2, and increased by about 3\% in CG. In contrast, HDL cholesterol levels increased in the training groups, more clearly in the HIIT group, but remained unchanged in the control group. Plasma triglycerides decreased by about $8 \%$ in the HIIT group and by about $5 \%$ in the normal training group, and increased by about $4 \%$ in the control group (Table 3 and Figure 2).

\section{Discussion}

This study showed a significant increase in MAV and $\mathrm{VO}_{2 \max }$ after 12 weeks in both experimental groups, which was more

Table 2 Morphological characteristics at inclusion (basal) and after 12 weeks in EGI, EG2, and CG

\begin{tabular}{|c|c|c|c|c|c|c|}
\hline & \multicolumn{2}{|l|}{ EGI $(n=8)$} & \multicolumn{2}{|c|}{$\operatorname{EG2}(n=8)$} & \multicolumn{2}{|l|}{ CG $(n=8)$} \\
\hline & Basal & I 2 weeks & Basal & I 2 weeks & Basal & I 2 weeks \\
\hline Age (years) & $22.5 \pm 1.77$ & & $22.4 \pm 1.41$ & & $24.0 \pm 1.69$ & \\
\hline Weight (kg) & $73.1 \pm 3.52$ & $72.1 \pm 4.03 *$ & $73.3 \pm 7.94$ & $72.4 \pm 7.90 *$ & $71.0 \pm 7.35$ & $71.7 \pm 7.64$ \\
\hline Height (m) & $1.79 \pm 0.04$ & $1.80 \pm 0.04$ & $1.68 \pm 0.28$ & $1.68 \pm 0.28$ & $1.75 \pm 0.07$ & $1.76 \pm 0.07$ \\
\hline BMI $\left(\mathrm{kg} / \mathrm{m}^{2}\right)$ & $22.8 \pm 1.71$ & $22.4 \pm 1.88 *$ & $23.0 \pm 1.38$ & $22.7 \pm 1.42^{*}$ & $23.0 \pm 1.95$ & $23.1 \pm 1.93$ \\
\hline
\end{tabular}

Notes: Data are expressed as the mean \pm standard deviation. $* P<0.05$, significant difference before - after training in the same group.

Abbreviations: BMI, body mass index; EGI, intermittent training group; EG2, usual football training group; CG, control group. 

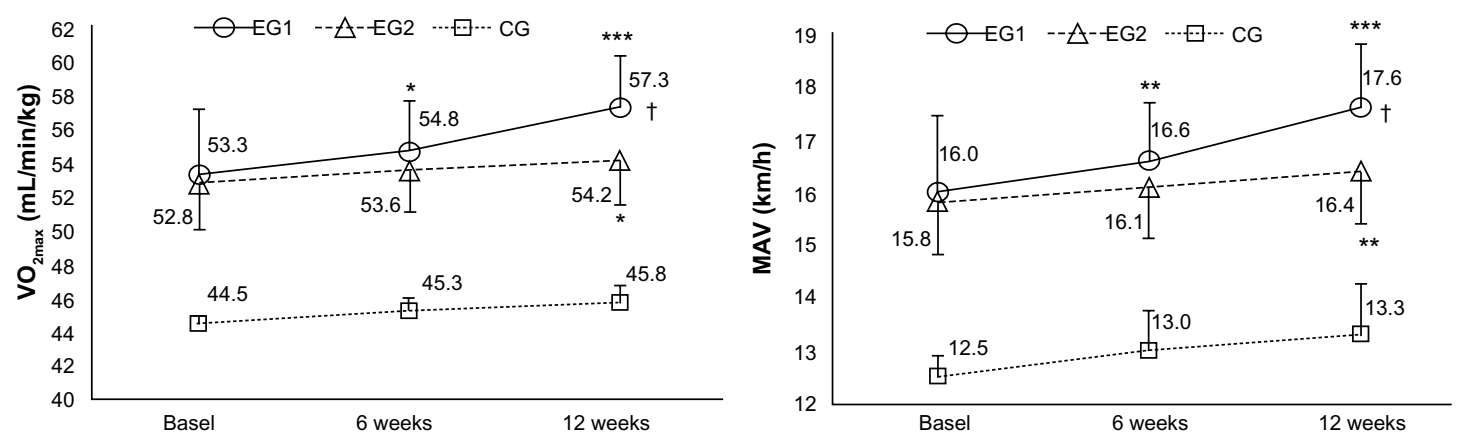

Figure I Maximal aerobic velocity and maximal oxygen uptake at inclusion (basal) and after 6 and I2 weeks of a training program in $E G I$, EG2, and $C G$. $* P<0.05$; $* * P<0.0$; $* * * P<0.00$ I (compared with respective basal value), and ${ }^{+} P<0.05$ (EGI versus $E G 2$ ).

Abbreviations: MAV, maximal aerobic velocity; EGI, intermittent training group; EG2, usual football training group; CG, control group.

noticeable in the HIIT group. It also showed a non-significant improvement in the lipid profile in both the HIIT and normal training groups.

We found that aerobic capacity increased earlier (after 6 weeks), and more importantly, at 12 weeks in players performing additional short-short HIIT compared with those doing ordinary training. Our data suggest a beneficial effect of intermittent training during the competitive phase in soccer players.

Several studies have reported increased aerobic capacity after intermittent exercise of short duration and high intensity. ${ }^{23,25-28}$ Daussin et al ${ }^{29,30}$ concluded that interval training is more effective than continuous training in improving $\mathrm{VO}_{2 \max }$ in sedentary subjects, and it has suggested that intermittent exercise is beneficial for soccer players. ${ }^{23,26,31,32}$ A high aerobic capacity allows soccer players to improve their performance. Balsom et al ${ }^{33}$ suggests that an interval training program allows players to limit their production of lactic acid and to increase their use of creatine phosphate during exercise. Finally, changes in aerobic capacity might also be related to changes in body mass. ${ }^{34}$

Previous studies that tested the effect of training on plasma lipids yielded conflicting data. Some studies showed that physical training has no significant effect on the lipid profile. ${ }^{16-18,35}$ Kishali et al, ${ }^{13}$ in a study involving subjects with different levels of physical training (20 male elite athletes, 44 trained men and 51 trained women, and 51 sedentary women) found no significant difference in plasma lipids between these groups. These authors reported that HDL cholesterol was higher in females than in sedentary and trained males, and that LDL cholesterol was lower in females (both sedentary and trained) than in males. They concluded that changes in the lipid and lipoprotein profile are more related to sex than to exercise. Other studies reported that training results in significant changes in the lipid profile in athletes ${ }^{11,36}$ as well as in untrained subjects who practice continued or intermittent aerobic training. ${ }^{7,937-39}$

Discrepancies between previous findings could be explained by several factors, such as study characteristics (method of randomization, dropout information), subject characteristics (race/ethnicity, taking of drugs that could affect plasma lipids, smoking, alcohol consumption, diet, previous physical activity), period of inclusion (preparative/competitive phase), training intensity (low/moderate/ high) and type (continuous or long/moderate/short intermittent training), timing of post-exercise blood draw, and environmental characteristics (eg, geography, season, and climate).

Previous studies that have tested the effect of training on plasma lipids have generally focused on untrained subjects

Table 3 Plasma lipids at inclusion (basal) and after 6 and 12 weeks in EGI, EG2, and CG

\begin{tabular}{|c|c|c|c|c|c|c|c|c|c|}
\hline & \multicolumn{3}{|c|}{ EGI $(n=8)$} & \multicolumn{3}{|c|}{$E G 2(n=8)$} & \multicolumn{3}{|c|}{ CG $(n=8)$} \\
\hline & Basal & 6 weeks & 12 weeks & Basal & 6 weeks & 12 weeks & Basal & 6 weeks & 12 weeks \\
\hline TC (mg/dL) & $161 \pm 15$ & $158 \pm 16$ & $158 \pm 16$ & $145 \pm 27$ & $144 \pm 27$ & $144 \pm 26$ & $149 \pm 27$ & $|50 \pm 3|$ & $152 \pm 33$ \\
\hline TG (mg/dL) & $86 \pm 23$ & $85 \pm 23$ & $79 \pm 19$ & $86 \pm 31$ & $88 \pm 27$ & $79 \pm 24$ & $78 \pm 15$ & $78 \pm 18$ & $8 I \pm 16$ \\
\hline LDL-C (mg/dL) & $105 \pm 13$ & $103 \pm 16$ & $103 \pm 16$ & $89 \pm 24$ & $89 \pm 25$ & $90 \pm 24$ & $96 \pm 23$ & $99 \pm 27$ & $100 \pm 28$ \\
\hline HDL-C (mg/dL) & $38 \pm 6.0$ & $38 \pm 7.0$ & $39 \pm 8.0$ & $38 \pm 9.0$ & $38 \pm 9.0$ & $38 \pm 8.0$ & $37 \pm 8.0$ & $36 \pm 7.0$ & $36 \pm 8.0$ \\
\hline
\end{tabular}

Note: Data are expressed as the mean \pm standard deviation.

Abbreviations: TC, total cholesterol; TG, triglycerides; LDL-C, low-density lipoprotein cholesterol; HDL-C, high-density lipoprotein cholesterol; EG I, intermittent training group; EG2, usual football training group; CG, control group. 

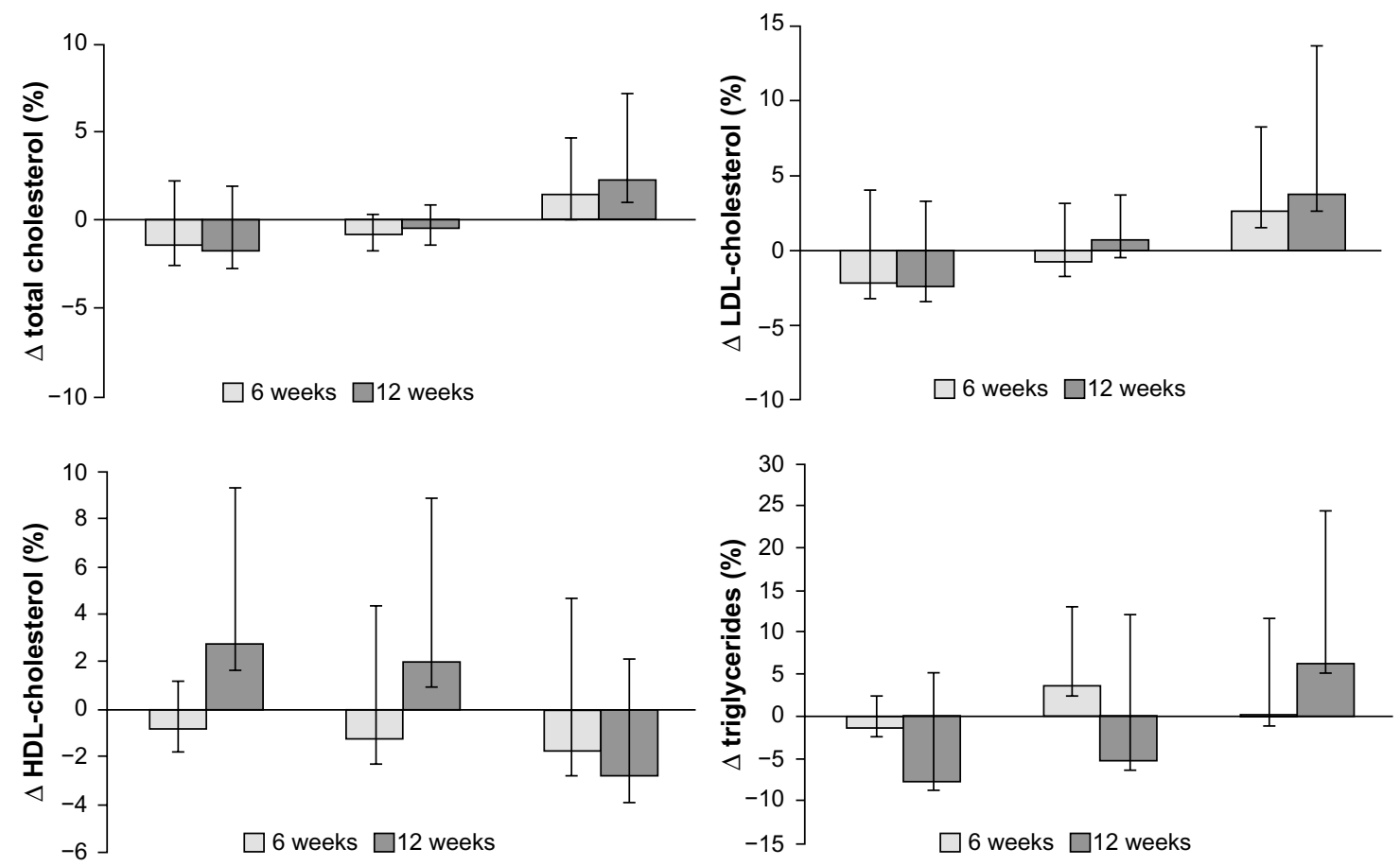

Figure 2 Changes in plasma total, LDL, and HDL cholesterol, and triglyceride (in percentage) levels at 6 and I 2 weeks of the training program in experimental group I (EGI), experimental group 2 (EG2), and a control group (CG).

Abbreviations: HDL, high-density lipoprotein; LDL, low-density lipoprotein.

and have often included continuous or long-long intermittent training programs. The present study used a short-short intermittent training program during the competitive phase in soccer players. It showed a superior improvement of the lipid profile in the HIIT group when compared with a normally training group and a control group. Although these changes are not statistically significant, their health benefit would be important. Indeed, a $1 \%$ decrease in total cholesterol or LDL cholesterol levels may reduce the risk of coronary artery disease by $2 \% .{ }^{40,41}$ Further, a $1 \%$ decrease in HDL cholesterol has been associated with a $2 \%-3 \%$ increase in coronary heart disease. ${ }^{42}$

The present study has some limitations. First, the intervention program was of short duration. Second, the relatively small number of participants may have underpowered the study, although significant and interesting results were shown for aerobic capacity. Finally, the effect of external factors, such as dietary intake and energy expenditure, as well as alcohol consumption, may have affected the lipid profile. ${ }^{43}$ These factors should be controlled for in future studies. Overall, our findings suggest that 12 weeks of shortshort HIIT has a beneficial effect on aerobic capacity. It also induces small changes in the lipid profile that, despite not being statistically significant, would have favorable effects on cardiovascular health.

\section{Disclosure}

The authors report no conflicts of interest in this work.

\section{References}

1. Ervin RB. Prevalence of metabolic syndrome among adults 20 years of age and over, by sex, age, race and ethnicity, and body mass index: United States, 2003-2006. Natl Health Stat Report. 2009;5:1-7.

2. Ben Ounis O, Elloumi M, Ben Chiekh I, et al. Effects of two-month physical-endurance and diet-restriction programs on lipid profiles and insulin resistance in obese adolescent boys. Diabetes Metab. 2008;34:595-600.

3. Kim JW, Kim DY. Effects of aerobic exercise training on serum sex hormone binding globulin, body fat index, and metabolic syndrome factors in obese postmenopausal women. Metab Syndr Relat Disord. 2012;10:452-457.

4. Mathunjwa ML, Semple SJ, du Preez C. A 10-week aerobic exercise program reduces cardiometabolic disease risk in overweight/obese female African university students. Ethn Dis. 2013;23:143-148.

5. Zorba E, Cengiz T, Karacabey K. Exercise training improves body composition, blood lipid profile and serum insulin levels in obese children. J Sports Med Phys Fitness. 2011;51:664-669.

6. Kelley GA, Kelley KS. Aerobic exercise and lipids and lipoproteins in men: a meta-analysis of randomized controlled trials. J Mens Health Gend. 2006;3:61-70.

7. Toriola AL. Influence of 12-week jogging on body fat and serum lipids. Br J Sports Med. 1984;18:13-17.

8. Afzalpour ME, Gharakhanlou R, Gaeini AA, Mohebbi H, Hedayati M, Khazaei M. The effects of aerobic exercises on the serum oxidized LDL and total antioxidant capacity in non-active men. CVD Prevention and Control. 2008;3:77-82.

9. Baker TT, Allen D, Lei KY, Willcox KK. Alterations in lipid and protein profiles of plasma lipoproteins in middle-aged men consequent to an aerobic exercise program. Metabolism. 1986;35:1037-1043. 
10. LeMura LM, von Duvillard SP, Andreacci J, Klebez JM, Chelland SA, Russo J. Lipid and lipoprotein profiles, cardiovascular fitness, body composition, and diet during and after resistance, aerobic and combination training in young women. Eur J Appl Physiol. 2000;82:451-458.

11. Farsani PA, Rezaeimanesh D. The effect of six-week aerobic interval training on some blood lipids and $\mathrm{VO}_{2}$ max in female athlete students. Procedia Soc Behav Sci. 2011;30:2144-2148.

12. Kim J, Lee N, Trilk J, et al. Effects of sprint interval training on elite Judoists. Int J Sports Med. 2011;32:929-934.

13. Kishali NF, Imamoglu O, Kaldirimci M, Akyol P, Yildirim K. Comparison of lipid and lipoprotein values in men and women differing in training status. Int J Neurosci. 2005;115:1247-1257.

14. Petridou A, Lazaridou D, Mougios V. Lipidemic profile of athletes and non-athletes with similar body fat. Int J Sport Nutr Exerc Metab. 2005; $15: 425-432$.

15. Sutherland WH, Nye ER, Boulter CP, Shelling A. Physical training plasma lipoproteins and faecal steroid excretion in sedentary men. Clin Physiol. 1988;8:445-452.

16. Tater D, Leglise D, Person B, Lambert D, Bercovici JP. Lipoproteins status in professional football players after period of vacation and one month after a new intensive training program. Horm Metab Res. 1987;19:24-27.

17. Thomas TR, Adeniran SB, Etheridge GL. Effects of different running programs on VO2 max, percent fat, and plasma lipids. Can J Appl Sport Sci. 1984;9:55-62.

18. Thomas TR, Adeniran SB, Iltis PW, Aquiar CA, Albers JJ. Effects of interval and continuous running on HDL-cholesterol, apoproteins A-1 and B, and LCAT. Can J Appl Sport Sci. 1985;10:52-59.

19. Bangsbo J. The physiology of soccer. With special reference to intense intermittent exercise. Thesis in exercise physiology. Copenhagen, Denmark: University of Copenhagen; 1994.

20. Krustrup P, Mohr M, Amstrup T, et al. The Yo-Yo intermittent recovery test: physiological response, reliability, and validity. Med Sci Sports Exerc. 2003;35:697-705.

21. Dupont G, Defontaine M, Bosquet L, Blondel N, Moalla W, Berthoin S. Yo-Yo intermittent recovery test versus the University de Montréal track test: relation with a high-intensity intermittent exercise. J Sci Med Sport. 2010;13:146-150

22. Dellal A, Barrieu P, Castagna C, et al. From training to performance in soccer. In: Billat V, eds. Physiology and methodology of training. From theory to practice. Brussels: De Boeck University, 1998. p. 254-257.

23. Dupont G, Blondel N, Lensel G, Berthoin S. Critical velocity and time spent at a high level of $\mathrm{VO}_{2}$ for short intermittent runs at supra maximal velocities. Can J Appl Physiol. 2002;27:103-115.

24. Friedewald WT, Levy RI, Fredrickson DS. Estimation of the concentration of low-density lipoprotein cholesterol in plasma, without use of the preparative ultracentrifuge. Clin Chem. 1972;18:499-502.

25. Billat VL, Hamard L, Koralsztein JP. The influence of exercise duration at $\mathrm{VO}_{2 \max }$ on the off-transient pulmonary oxygen uptake phase during high intensity running activity. Arch Physiol Biochem. 2002;110: 383-392.

26. Dupont G, Blondel N, Berthoin S. Performance for short intermittent runs: active versus passive recovery. Eur J Appl Physiol. 2003;89: $548-554$.
27. Dupont G, Akakpo K, Berthoin S. The effect of in-season, highintensity interval training in soccer players. J Strength Cond Res. 2004:18:584-589.

28. Helgerud J, Høydal K, Wang E, et al. Aerobic high-intensity intervals improve $\mathrm{VO}_{2 \max }$ more than moderate training. Med Sci Sports Exerc. 2007:39:665-671.

29. Daussin FN, Ponsot E, Dufour SP, et al. Improvement of VO2 max by cardiac output and oxygen extraction adaptation during intermittent versus continuous endurance training. Eur J Appl Physiol. 2007;101:377-383.

30. Daussin FN, Zoll J, Dufour SP, et al. Effect of interval versus continuous training on cardiorespiratory and mitochondrial functions: relationship to aerobic performance improvements in sedentary subjects. Am J Physiol Regul Integr Comp Physiol. 2008;295(1):R264-R272.

31. Billat V. Physiology and methodology of training. From theory to practice. Brussels: De Boeck University, 1998. pp 224.

32. Helgerud J, Engen LC, Wisloff U, Hoff J. Aerobic endurance training improves soccer performance. Med Sci Sports Exerc. 2001;33: 1925-1931.

33. Balsom PD, Ekblom B, Söderlund K, Sjödin B, Hultman E. Creatine supplementation and dynamic high-intensity intermittent exercise. Scand J Med Sci Sports. 1993;3:143-149.

34. Nikolaidis PT. Cardiorespiratory power across adolescence in male soccer players. Hum Physiol. 2011;37:636-641.

35. Gaesser GA, Rich RG. Effects of high- and low-intensity exercise training on aerobic capacity and blood lipids. Med Sci Sports Exerc. 1984;16:269-274.

36. Manna I, Khanna GL, Chandra Dhara P. Effect of training on physiological and biochemical variables of soccer players of different age groups. Asian J Sports Med. 2010;1:5-22.

37. Musa DI, Adeniran SA, Dikko AU, Sayers SP. The effect of a highintensity interval training program on high-density lipoprotein cholesterol in young men. $J$ Strength Cond Res. 2009;23:587-592.

38. Altena TS, Michaelson JL, Ball SD, Guilford BL, Thomas TR. Lipoprotein subfraction changes after continuous or intermittent exercise training. Med Sci Sports Exerc. 2006;38:367-372.

39. Hespel P, Lijnen P, Fagard R, Van Hoof R, Rosseneu M, Amery A. Changes in plasma lipids and apoproteins associated with physical training in middle-aged sedentary men. Am Heart J. 1988;115: 786-792.

40. Ernst ND. Consensus Development Panel on lowering blood cholesterol to prevent heart disease: implications for dietitians. J Am Med Assoc. 1985;85:586-588.

41. Pedersen TR, Olsson AG, Faergeman O, et al. Lipoprotein changes and reduction in the incidence of major coronary heart disease events in the Scandinavian Simvastatin Survival Study (4S). Circulation. 1998;97:1453-1460.

42. Gordon DJ, Probstfield JL, Garrison RJ, et al. High-density lipoprotein cholesterol and cardiovascular disease: four prospective American studies. Circulation. 1989;79:8-15.

43. Rimmer JH, Looney MA. Effects an aerobic activity program on the cholesterol levels of adolescents. Res Q Exerc Sport. 1997;68:74-79.
Open Access Journal of Sports Medicine

\section{Publish your work in this journal}

Open Access Journal of Sports Medicine is an international, peer-reviewed, open access journal publishing original research, reports, reviews and commentaries on all areas of sports medicine. The manuscript management system is completely online and includes a very quick and fair peer-review system.

\section{Dovepress}

Visit http://www.dovepress.com/testimonials.php to read real quotes from published authors. 